\title{
Análise de Desempenho de Detectores Multi-Usuários Lineares para Sistemas DS-CDMA
}

\section{Linear Multiuser Performance to DS-CDMA Systems}

Fernando Ciriaco Dias Neto ${ }^{1}$, Taufik Abrão ${ }^{2}$, Paul Jean E. Jeszensky ${ }^{3}$

\section{Resumo}

Neste trabalho foram obtidas expressões simplificadas e relativamente precisas para a BER (Bit Error Rate) para os principais detectores multi-usuários lineares (Convencional, Descorrelacionador e MMSE) síncronos e assíncronos em canais AWGN e Rayleigh Plano. Faz-se uma análise da validade das expressões analíticas através de resultados de desempenho via simulação Monte-Carlo (MCS). Palavras-chaves: Detectores Multi-Usuários. MMSE. Descorrelacionador. Taxa de Erro de Bit

\begin{abstract}
Simplified and relatively accurate BER (Bit Error Rate) expressions were obtained in this work, for the Decorelator and MMSE over AWGN and Flat Rayleigh channels. Analysis of the expressions validity is made comparing analytically obtained results with those obtained through Monte-Carlo simulation (MCS).

Key words: Multiuser Detection; MMSE; Decorelator; Direct Sequence Code Division Multiple Access Systems; BER (Bit Error Rate).
\end{abstract}

1 Universidade Estadual de Londrina - Centro de Tecnologia e Urbanismo, $4^{\circ}$ ano do curso de graduação em Engenharia, Comunicações sem fio, sistemas DS/CDMA quase-síncronos e Detectores Multiusuários para DS/CDMA, E-mail: fernandociriaco@onda.com.br.

2 Universidade Estadual de Londrina - Centro de Tecnologia e Urbanismo, graduado, mestre e doutor em Engenharia, Professor adjunto do Departamento de Engenharia Elétrica da Universidade Estadual de Londrina, PR. E-mail: taufik@uel.br

3 PTC-EPUSP - Depto de Engenharia de Telecomunicações e Controle da Escola Politécnica da USP, Engenheiro Eletricista, Mestre Doutor em Engenharia Elétrica e Livre Docente na área de Telecomunicações. E-mail: pjj@lcs.poli.usp.br 


\section{Introdução}

Nos últimos anos os serviços de comunicação sem fio vêm sofrendo grandes mudanças para poder atender a explosão na demanda de serviços de voz, dados e imagem ( $3^{\mathrm{a}}$ Geração). Para que esses serviços sejam oferecidos com qualidade, grupos de pesquisas em todo o mundo vêm fazendo grandes esforços na busca de sistemas de comunicação sem fio de alta eficiência espectral com capacidade e desempenhos melhorados, quer seja em termos do número máximo de usuários por unidade de área suportado em uma mesma banda, quer seja na obtenção de sistemas móveis capazes de atender essa diversidade de serviços. O sistema DS-CDMA (Direct Sequence) Code-Division Multiple Access) Convencional (ou Single-User) oferece grandes vantagens, como capacidade soft, facilidade de obtenção de handover soft, rejeição à interferência de banda estreita e possibilidade de exploração da diversidade multipercurso, mas ele ainda é afetado pela interferência de múltiplo acesso (MAI - Multiple Access Interference) e pelo efeito near-far (NFRes). Disso resulta um sistema cuja capacidade sistêmica está bem abaixo da capacidade do canal e, assim, uma análise de detectores multi-usuários se faz necessária, pois estes se mostram tolerantes aos desajustes de potência e combatem efetivamente a interferência de múltiplo acesso, do que decorre a melhoria de desempenho em relação ao detector Convencional (T. ABRÃO, 2001).

Este trabalho divide-se em 7 seções. Inicialmente, a seção 2 trata das definições do modelo dos detectores utilizados nas seções seguintes. Na seção 3 são apresentadas as expressões para a BER para os tipos de canal analisados. Na seção 4 é mostrada a validade das aproximações para algumas características de seqüências aleatórias.

Na seção 5, são obtidas as BERs para os principais detectores MUD em canal AWGN (Additive White Gaussian Noise), Descorrelacionador e MMSE. A partir das expressões analíticas para a relação sinalruído mais interferência média, $\overline{R S R I}$, apresentadas na seção anterior, obteve-se a BER analítica simplificada para os detectores em canal com Desvanecimento Plano (Rayleigh Flat). Adicionalmente, são comparados os resultados obtidos através das simulações e das expressões encontradas nas seções anteriores, salientando-se a região de validade destas expressões analíticas. A seção 6 apresenta resultados de desempenho para canal Rayleigh Plano. Por fim, na seção 7 são apresentadas as principais conclusões deste estudo.

\section{Modelo do Sistema}

Em um sistema DS-CDMA, o sinal recebido pode ser descrito por:

$$
y(t)=\sum_{k=1}^{N} A_{k} b_{k} s_{k}\left(t-\tau_{k}\right) \cos \left(2 \pi f_{0} t+\phi_{k}\right)
$$

onde: $t \in\left[0, T_{b}\right]$ e $T_{b}$ é o período de bit, $A_{k}=$ amplitude recebida do sinal do $k$-ésimo usuário, $b_{k} \in\{-1,+1\}=$ bit de informação transmitido pelo $k$-ésimo usuário e $s_{k}=$ seqüência de assinatura atribuída ao $k$-ésimo usuário. Na transmissão síncrona, o termo atraso para qualquer sinal recebido é $\tau_{k}=0$.

O modelo de transmissão-recepção analisado é descrito na Fig. 1. O receptor é constituído de um banco de filtros casados, seguido de uma transformação linear cuja finalidade é minimizar o efeito destrutivo do canal e da interferência de múltiplo acesso. A matriz de transformação linear, T, é dada respectivamente por (S. VERDÚ, 1998):

- Convencional: $\mathrm{T}=I$

- Descorrelacionador: $\mathrm{T}=R^{-1}$

- MMSE : $\mathrm{T}=\left(R+\sigma^{2} A^{-2}\right)^{-1}$

onde $I$ é a matriz identidade, $R^{-1}$ sendo a matriz inversa da matriz de correlação cruzada entre as seqüências de espalhamento, $A^{-2}$ sendo a matriz diagonal das amplitudes e $s^{2}$ a potência do ruído. Neste trabalho foi considerada modulação da portadora do tipo BPSK, controle perfeito de potência 
dos sinais recebidos, seqüências de assinatura aleatórias e sinais recebidos síncronos e assíncronos ao nível de chip.

\section{Taxa de Erro de Bit (BER)}

Quando analisamos um determinado receptor devemos levar em consideração o canal pelo qual a informação é transmitida. Em um canal AWGN, a BER para um sistema DS-CDMA com modulação BPSK é dada por (J. PROAKIS, 1989), (S. M. KAY) :

$$
P_{b}=Q(\sqrt{2 \overline{R S R I}})
$$

onde $Q(x)$ é a função de erro complementar gaussiana e $\overline{R S R I}$ é a relação sinal-ruído mais interferência média.

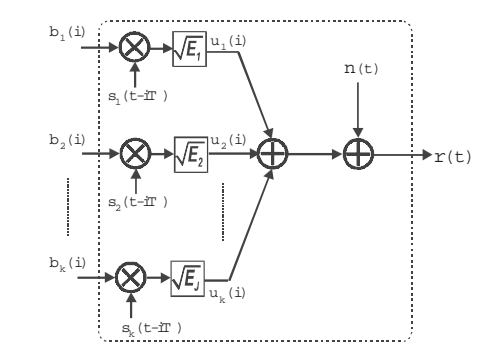

(a) Transmissor + Canal

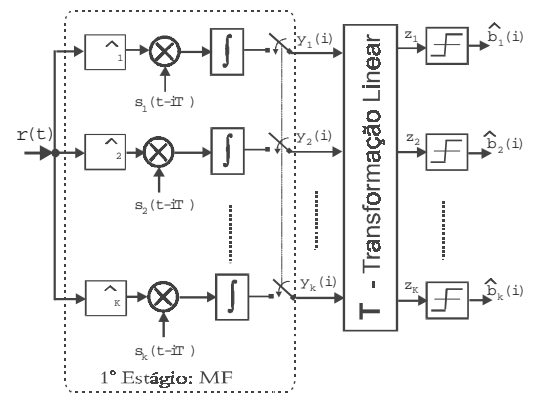

(b) Receptor

Figura 1. (a) Modelo de transmissão e (b) recepção utilizados na modelagem do sistema

A BER em um canal com desvanecimento seletivo em freqüência Rayleigh pode ser calculada por (J. PROAKIS, 1989):

$P_{b}=\left[\frac{1}{2}\left(1-\frac{1}{\sqrt{1+\frac{1}{\text { RSRI }_{j}}}}\right)\right]^{P} \cdot \sum_{j=0}^{P-1}\left(\begin{array}{c}P-1+j \\ j\end{array}\right)\left[\frac{1}{2}\left(1-\frac{1}{\sqrt{1-\frac{1}{\text { RSRI }_{j}}}}\right)\right]^{j}$ onde $\mathrm{P}=$ número de percursos e $\overline{R S R I_{j}}$ é o valor médio para a relação $R S R I$ do sinal do $j$-ésimo percurso.

As expressões analíticas (2) e (3) valem para recepção síncrona e assíncrona, mudando apenas o parâmetro $\overline{R S R I}$. O parâmetro $\overline{R S R I}$ é dado por:

$$
\overline{R S R I_{k j}}=\frac{m_{k j}^{2}}{2 \sigma_{k j}^{2}}
$$

na qual $m_{k j}^{2}$ é a média do sinal recebido à saída do filtro casado considerando o $k$-ésimo usuário e $j$-ésimo percurso; e $\sigma_{k j}^{2}$ é a variância desse mesmo sinal.

Em (J. PROAKIS, 1989) e (R. K. MORROW JR; J.S.LENHERT, 1989), mostra-se que a $\overline{R S R I}$ para os detectores multiusuários lineares em canal seletivo em freqüência é a mesma para o canal AWGN, considerando a hipótese simplificadora de que os $P$ raios que chegam ao receptor sujeito a um canal Rayleigh Multipercurso possuem o mesmo valor médio quadrático, isto é, apresentam um perfil atrasopotência uniforme.

\section{Seqüências Aleatórias e Determinísticas}

$\mathrm{Na}$ recepção de sistemas DS-CDMA, os sinais são demodulados separadamente para cada usuário, mas os outros usuários interferem nesta demodulação, o que é chamada de interferência de múltiplo acesso (MAI).

Essa interferência é basicamente determinada pelos valores de correlação cruzada e pela disparidade de potência entre o usuário de interesse e os interferentes. Quanto maior for o valor da correlação cruzada, maior será a MAI e pior será o desempenho do receptor. Portanto, a escolha de seqüências de espalhamento com boas propriedades de correlação cruzada deve ser feita para que haja uma melhoria no desempenho dos receptores. Podese reduzir o efeito da MAI estabelecendo um controle das potências recebidas relativamente eficaz ${ }^{1}$ ou 
utilizando-se detectores robustos ao efeito near-far, como o detector Descorrelacionador e o MMSE.

Dadas as seqüências de espalhamento normalizadas (energia unitária):

$$
\left\|S_{n}\right\|^{2}=\frac{1}{T} \int_{0}^{T_{b}} S_{n}^{2}(t) d t=1
$$

na qual $t \in\left[0, T_{b}\right]$ e $T_{b}$ é o período de bit, o grau de semelhança entre as seqüências (correlação cruzada) é definida como:

$$
\rho_{i j}=\left\langle s_{i}, s_{j}\right\rangle=\frac{1}{T} \int_{0}^{T} s_{i}(t) \cdot s_{j}(t) d t
$$

Por meio da desigualdade de Cauchy-Schwarz e da equação em (5), temos:

$$
\left|\rho_{i j}\right|=\left|\left\langle s_{i}, s_{j}\right\rangle\right| \leq\left\|s_{i}\right\| \cdot\left\|s_{j}\right\|=1
$$

Isso garante que $-1 \leq \rho_{i j} \leq 1$ e $0 \leq\left|\rho_{i j}\right| \leq 1$.

$\mathrm{Na}$ obtenção de expressões simplificadas para a BER dos receptores analisados devemos encontrar expressões também simplificadas para as principais características das seqüências, como a magnitude da correlação cruzada média, a correlação cruzada média e a correlação cruzada média quadrática.

Considerando seqüências aleatórias, temos:

a) A correlação cruzada média é bem conhecida e dada por (S. VERDÚ, 1998):

$$
E\left[\rho_{i j}\right]=0
$$

pois considera-se que as seqüências são formadas por valores $\{-1,+1\}$ independentes e igualmente distribuídos.

b) O momento de segunda ordem da correlação cruzada, ou seja, a correlação cruzada quadrática média também é bem conhecida e dada por (M. B. PURSLEY, 1977) e (S. VERDÚ, 1998):

$$
\begin{aligned}
& E\left[\rho_{i j}^{2}\right]=\frac{1}{G} \quad \text { (síncrono) } \\
& E\left[\rho_{i j}^{2}\right]=\frac{1}{3 G} \quad \text { (assíncrono) }
\end{aligned}
$$

onde $\mathrm{G}=$ ganho de processamento, que para códigos curtos, resulta em $G=T_{b} / T_{c}$, sendo $T_{c}$ o período de chip.

Estas propriedades podem ser visualizadas por meio das Figs. 2 e 3, onde foram obtidos resultados via simulação Monte-Carlo para efeito de comparação com os valores teóricos dados pelas equações (7), (8) e (9).

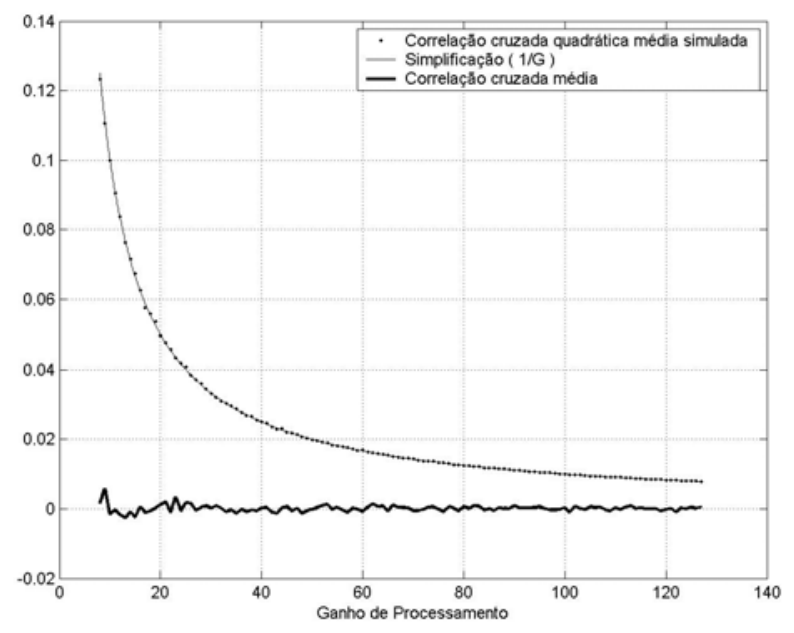

Figura 2. Comparaçāo entre os valores de correlação cruzada média e quadrática média de sequências aleatórias no caso síncrono; média sobre 5000 amostras de matrizes de 10 sequências e valores obtidos através da equação (8).

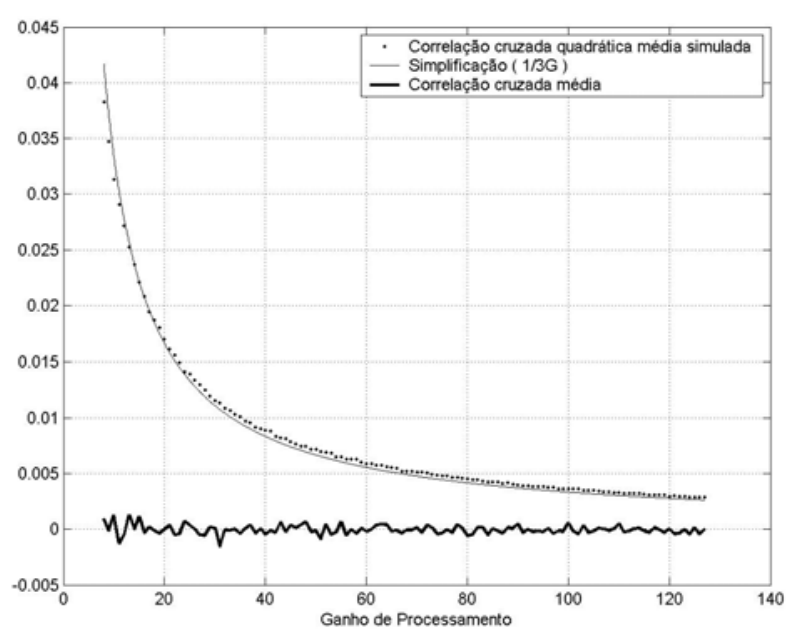

Figura 3. Comparação entre os valores de correlação cruzada média e quadrática média de sequências aleatórias no caso assíncrono, considerando média sobre 1000 amostras de matrizes de 10 sequências e valores obtidos através da equação (9). 
Outra propriedade muito importante é a magnitude da correlação cruzada média, pois é esta componente que praticamente constitui a MAI. Esta magnitude não possui média zero como no caso da correlação cruzada média, equação (7), pois $E\left[\left|\rho_{i j}\right|\right] \neq 0$ onde $0 \leq\left|\rho_{i j}\right| \leq 1$.

Por meio de simulação, determinamos um valor aproximado para a magnitude da correlação cruzada média:

$$
\begin{aligned}
& E\left[\left|\rho_{i j}\right|\right] \approx \frac{1}{\sqrt{1,57 \cdot G}} \quad \text { (síncrono) } \\
& E\left[\left|\rho_{i j}\right|\right] \approx \frac{1}{\sqrt{5,2 \cdot G}} \quad \text { (assíncrono) }
\end{aligned}
$$

Estas aproximações podem ser avaliadas através da Fig. 4, onde estão mostrados resultados de simulação Monte-Carlo e calculados utilizando as expressões (10) e (11).

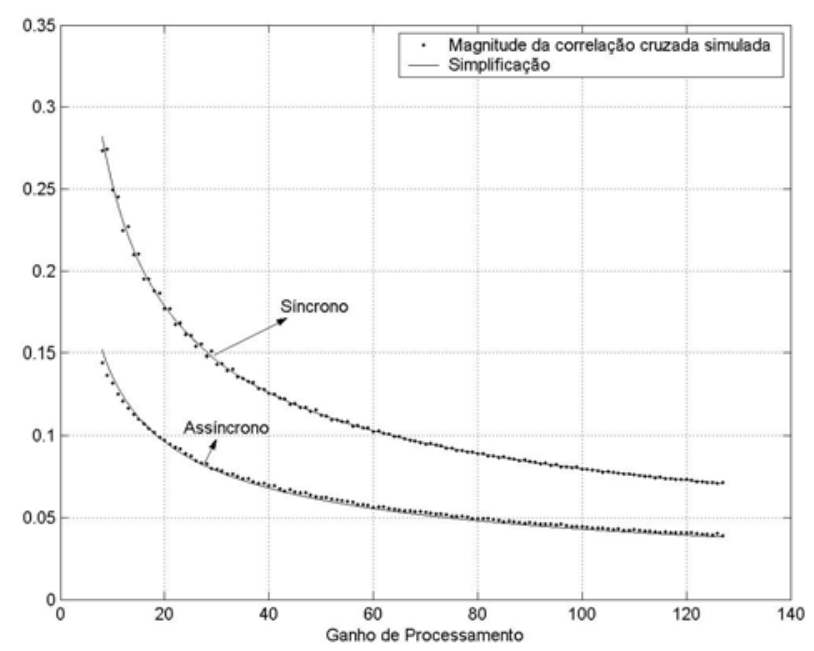

Figura 4. Comparação da simplificação feita para os valores da magnitude da correlação cruzada média em sequências aleatórias no caso síncrono e assíncrono, considerando média sobre 1000 amostras de matrizes de 10 sequências.

Note-se que para valores de ganho de processamento maiores que 8 , as simplificações propostas resultam em uma ótima convergência para os valores simulados.
Além das seqüências aleatórias, várias outras famílias de seqüências de espalhamento determinísticas foram propostas na literatura, como as de Gold, Kasami, as de máximo comprimento (SMC), entre outras. Estas famílias apresentam uma magnitude de correlação cruzada média baixa, propriedade esta que reduz substancialmente a MAI, mas estas famílias de seqüências possuem poucos elementos, o que restringe a quantidade de usuários ativos compartilhando o espectro de freqüência disponível.

Em contrapartida, seqüências de espalhamento aleatórias não apresentam limitação no tamanho do conjunto, pois podem ser geradas para qualquer número de usuários $\left(\leq 2^{\mathrm{N}}\right)$; no entanto, resultam em valores de correlação cruzada média superiores que os encontrados com seqüências determinísticas.

Desse modo, admite-se naturalmente a existência de uma relação custo-benefício na escolha do tipo de conjunto de seqüências de espalhamento (aleatórias versus determinísticas), pois deseja-se utilizar seqüências que possuam valores de magnitude da correlação cruzada média mais baixos possíveis e simultaneamente que possam suportar o maior número de usuários.

Uma comparação entre seqüências aleatórias e seqüências determinísticas em relação à magnitude da correlação cruzada é feita na Fig. 5. Note-se que as boas propriedades existentes nos conjuntos de seqüências determinísticas do tipo Gold e SMC, em termos dos valores da magnitude da correlação cruzada média, implica uma melhoria de desempenho dos receptores com o emprego deste tipo de seqüências. Em contrapartida, uso de seqüências aleatórias implicaria em desempenho inferior; no entanto, seqüências aleatórias podem ser geradas para qualquer número usuários e ganho de processamento. 


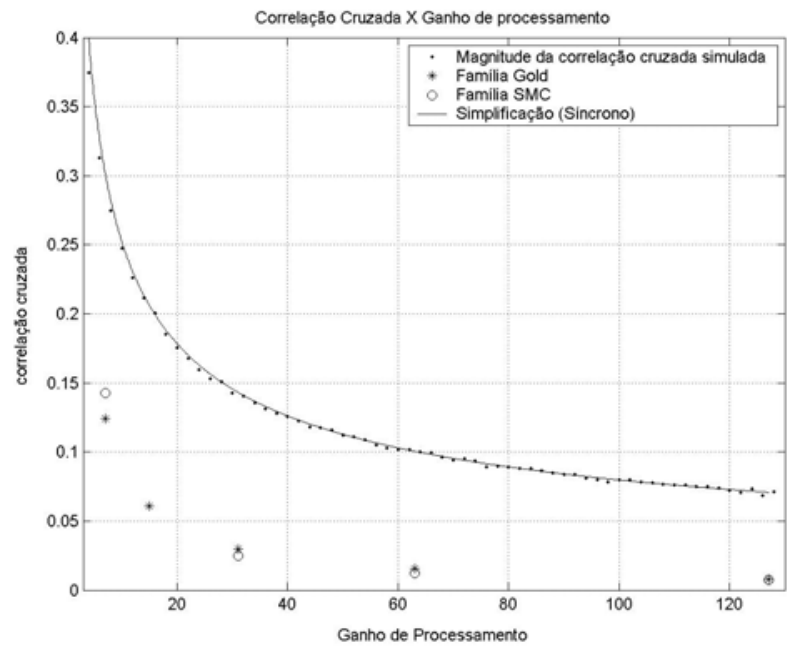

Figura 5. Comparação de valores da magnitude da correlação cruzada média no caso síncrono para diferentes tipos de seqüências de espalhamento.

\section{Desempenho de Detectores Multi-Usuário Lineares}

Esta seção analisa o desempenho dos receptores lineares Descorrelacionador, MMSE e Convencional, tanto do ponto de vista de simulação Monte-Carlo quanto analiticamente, propondo expressões simplificadas para a probabilidade de erro de bit $\left(P_{e}\right)$ no caso de receptores multi-usuários lineares com modulação BPSK e controle perfeito de potência.

\section{Simulações Monte-Carlo}

O método de simulação computacional empregado neste trabalho foi o Monte Carlo. Este método é muito utilizado quando não for possível determinar a probabilidade de erro de bit nem analiticamente e nem numericamente ou ainda quando se estiver investigando a validade de expressões (semi-) analíticas para o desempenho de novas estruturas e/ou sistemas de comunicação. $\mathrm{O}$ MCS é simplesmente um conjunto de seqüências de Bernoulli onde são computados os números de sucessos ou erros dividido pelo número de realizações (M.C. JERUCHIM; P. BALABAM; K.S.SHANMUGAM, 1992).

$$
P_{e}=\frac{n_{\text {erros }}}{\text { trials }}
$$

onde trials $=$ número de realizações independentes e $n_{\text {erros }}=$ número de erros obtidos nas realizações.

Quando trials $\rightarrow \infty$ a razão que define $P_{e}$ converge, mas sabemos que computacionalmente adotar trials $\rightarrow \infty$ é inviável.

Portanto, emprega-se um número tal de trials ou erros por ponto que conduza a um resultado dentro de um intervalo de confiança esperado. O menor número de erros $\left(n_{\text {erros }}\right)$ utilizado nas simulações foi de 200 erros por ponto, isto é, para uma $P_{e}$ esperada de $10^{-4}$, por exemplo, exige no mínimo $2 \times 10^{6}$ realizações!

Isso mostra que o tempo computacional é elevado, indicando que o uso das expressões analíticas simplificadas seja uma opção atraente.

O sistema Transmissão-Canal-Recepção foi descrito utilizando linguagem MatLab, desde a geração (aleatória) de bits de dados, transmissão, distorção e atenuação devido ao efeito do canal até a recepção utilizando detectores Convencional, Descorrelacionador e MMSE segundo o modelo apresentado no sistema da Fig.1.

\section{Receptor Convencional}

O Receptor Convencional em banda base constitui-se de um banco de correlatores casados às respectivas seqüências de espalhamento que identificam os usuários em um sistema de múltiplo acesso por divisão de código e seqüência direta, DS/ CDMA; os sinais são desespalhados, Fig.1.b, passam por integradores e amostradores. A operação de desespalhamento é feita a partir de uma réplica da seqüência de espalhamento no receptor, sincronizada ao sinal recebido do usuário de interesse. Estimativas de bits transmitidos são obtidas comparando-se os sinais amostrados com o limiar zero através de dispositivos de decisão abrupta. 
Utilizando uma notação matricial, o receptor Convencional pode ser descrito por uma transformação linear dada pela matriz identidade: $T=I$, Fig. 1.b.

\section{$\overline{R S R I}$ Para Detector Convencional}

O sinal à saída do banco de filtros casados (MFB), Fig. 1, pode ser caracterizado estatisticamente pelo $1^{\circ}$ e $2^{\circ}$ momento de um processo Gaussiano. A partir da média e variância do primeiro usuário, obtemos a $\overline{R S R I}$ (R. K. MORROW JR; J.S.LENHERT, 1989):

$$
\begin{aligned}
& \overline{R S R I}_{\text {Conv }}^{a s \sin c}=\frac{1}{\frac{2(K-1)}{3 G}+\frac{N_{0}}{E_{b}}}=\frac{1}{\frac{2 L}{3}+\frac{N_{0}}{E_{b}}} \\
& \overline{R S R I}_{\text {Conv }}^{\sin c}=\frac{1}{\frac{2(K-1)}{G}+\frac{N_{0}}{E_{b}}}=\frac{1}{2 L+\frac{N_{0}}{E_{b}}}
\end{aligned}
$$

onde $E_{b}$ é a energia por bit, $N_{0}$ é a densidade espectral de potência do Ruído AWGN, $L=\frac{K-1}{G}$ é o carregamento do sistema em termos de usuários interferentes, $K$ é o número de usuários e $G$ é o ganho de processamento.

Podemos encontrar a BER para o receptor convencional substituindo as expressões obtidas para a $\overline{R S R I}$ síncrono e assíncrono em (2) e (3), respectivamente.

\section{Regiões de Aplicabilidade das Expressões para Convencional}

A aplicabilidade da expressão simplificada para a BER do receptor convencional em canal AWGN síncrono pode ser confirmada através da Fig.6. Observe-se que a expressão analítica simplificada possui boa convergência quando o carregamento é baixo, porém, uma ótima convergência pode ser verificada quando o sistema estiver sob um carregamento maior que $20 \%$.

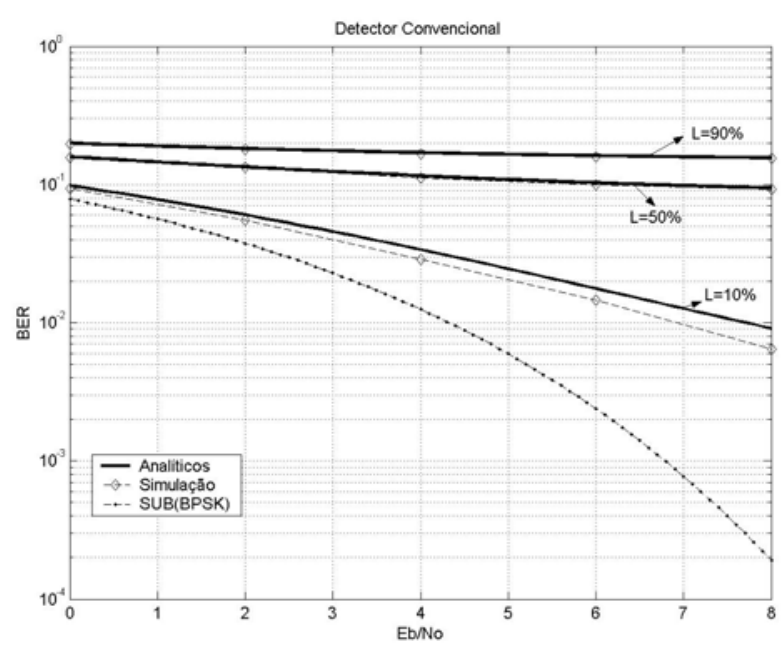

Figura 6. Probabilidade de Erro de Bits para um sistema com $E_{b} / N_{0}$ variável, canal AWGN síncrono, com carregamento de $10 \%, 50 \%$ e $90 \%$, com controle perfeito de potência e expressões analíticas simplificadas.

\section{Receptor Descorrelacionador}

O detector Descorrelacionador possui os mesmos estágios na recepção dos bits transmitidos que o detector Convencional, apenas acrescentando a transformação linear $T=R^{-1}$ antes da amostragem dos bits, onde $R^{-1}$ é a matriz inversa da matriz de correlação entre as seqüências de espalhamento dos usuários ativos. Essa matriz visa obter o desacoplamento dos sinais dos usuários interferentes, resultando em um receptor resistente ao efeito nearfar, mas ainda afetado pelo ruído de fundo.

\section{$\overline{R S R I}$ Para o Descorrelacionador}

De forma análoga ao receptor Convencional, à saída do bloco de transformação linear T, Fig. 1, determina-se a média e a variância para o sinal do $k$ ésimo usuário, resultando em (S. VERDÚ, 1998):

$$
\begin{aligned}
& \overline{\operatorname{RSII}}_{k}^{\mathrm{sinc}}=\frac{E_{b}}{N_{0}} \overline{\operatorname{AME}}_{k}^{\mathrm{sinc}} \\
& \overline{\operatorname{RSI}}_{k}^{\mathrm{assinc}}=\frac{E_{b}}{N_{0}} \overline{A M E}_{k}^{\mathrm{assinc}}
\end{aligned}
$$


na qual $\overline{A M E}$ é a eficiência assintótica multi-usuário média.

\section{Determinação da $\overline{A M E}$}

Para encontrarmos a BER do detector Descorrelacionador devemos encontrar uma expressão simplificada para a $\overline{A M E}$.

Para o $k$-ésimo usuário em um sistema DSCDMA síncrono, resulta (S. VERDÚ, 1998):

$$
A M E_{k}^{\mathrm{sinc}}=\frac{1}{R_{k k}^{-1}}
$$

na qual $R_{k k}^{-1}$ é o elemento da $k$-ésima linha e $k$ ésima coluna da matriz inversa de correlação.

A expressão para a AME no caso Assíncrono também é bem conhecida e dada por (S. VERDÚ, 1998):

$$
A M E_{k}^{\mathrm{assinc}}=\left(\frac{1}{2 \pi} \int_{-\pi}^{\pi}\left[S\left(e^{j \omega}\right)\right]_{k k}^{-1} d \omega\right)
$$

onde a matriz de correlação cruzada complexa é definida como: $S\left(e^{j \omega}\right)=R^{T}[1] e^{j \omega}+R[0]+R[1] e^{-j \omega}$, sendo o primeiro termo, a matriz de correlação cruzada parcial referente ao bit posterior, o termo central referente ao bit atual e o terceiro termo a matriz de correlação parcial referente ao bit posterior.

Na busca de uma expressão simplificada para a $\overline{A M E}$, encontramos primeiro a expressão da AME para 2 usuários e estendemos essa expressão para um número $\mathrm{K}$ de usuários.

Para 2 usuários, a AME para o $2^{\circ}$ usuário é definida como (S. VERDÚ, 1998):

$$
\begin{gathered}
A M E_{2}^{\text {sinc }}=1-\rho_{12}^{2} \\
A M E_{2}^{\text {assinc }}=\sqrt{\left[1-\left(\rho_{12}+\rho_{21}\right)^{2}\right]\left[1-\left(\rho_{12}-\rho_{21}\right)^{2}\right]}
\end{gathered}
$$

para os casos síncrono e assíncrono, respectivamente.

Aplicando o produto dentro da raiz em (19), obtemos:

$$
A M E_{2}^{\text {assinc }}=\sqrt{\left[1-\left(\rho_{12}^{2}+\rho_{21}^{2}\right)\right]^{2}-4 \rho_{12}^{2} \rho_{21}^{2}}
$$

Dessa forma, analisando-se o valor relativo de $\frac{4 \rho_{12}^{2} \rho_{21}^{2}}{\left[1-\left(\rho_{12}^{2}+\rho_{21}^{2}\right)\right]^{2}}$, Fig. 7, conclui-se que $4 \rho_{12}^{2} \rho_{21}^{2} \ll<\left[1-\left(\rho_{12}^{2}+\rho_{21}^{2}\right)\right]^{2}$ para qualquer ganho de processamento.

Observe que os valores relativos decrescem proporcionalmente com o aumento do ganho de processamento. Portanto, com um ganho de processamento maior que 20 percebe-se um efeito muito pequeno do numerador $4 \rho_{12}^{2} \rho_{21}^{2}$ em relação ao denominador $\left[1-\left(\rho_{12}^{2}+\rho_{21}^{2}\right)\right]^{2}$, mostrando que a utilização de seqüências aleatórias com ganho de processamento maior que 8 resulta em uma razão menor que $0,5 \%$. Essa razão é melhorada ainda utilizando-se seqüências determinísticas.

Outra análise pode ser feita com o auxílio da Fig. 8 , onde a razão $\frac{4 \rho_{12}^{2} \rho_{21}^{2}}{\left[1-\left(\rho_{12}^{2}+\rho_{21}^{2}\right)\right]^{2}}$ foi calculada em função de valores de correlação cruzada.

Verifica-se, por meio da Fig. 8, que para valores de $\bar{\rho}<0,3$, a razão não ultrapassa $5 \%$, diminuindo ainda mais para valores menores de $\rho_{i k}$.

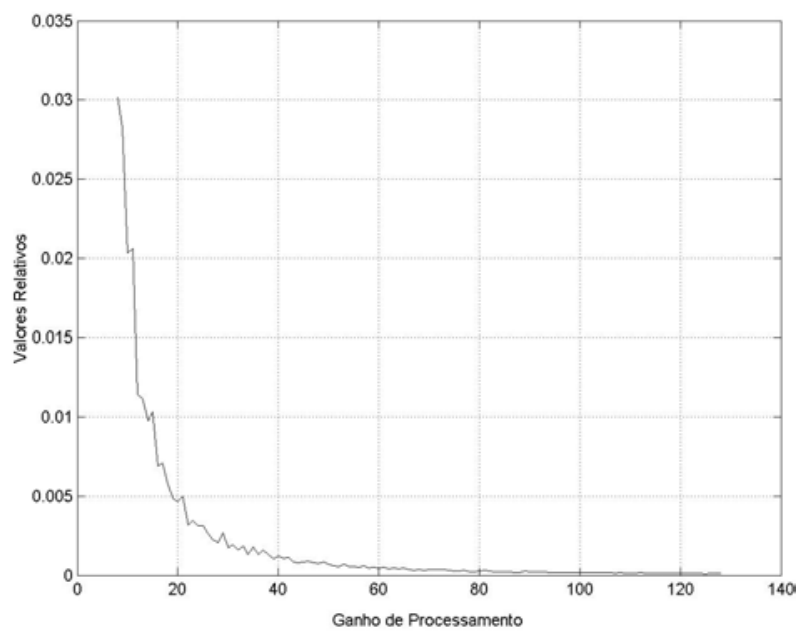

Figura 7. Influência da relação $\frac{4 \rho_{1}^{2} \rho_{21}^{2}}{\left[1-\left(\rho_{12}^{2}+\rho_{21}^{2}\right)^{2}\right]^{2}}$ em função do ganho de processamento, considerandosequências aleatórias e média sobre 1500 amostras de correlação cruzada, $\rho_{i k}$. 


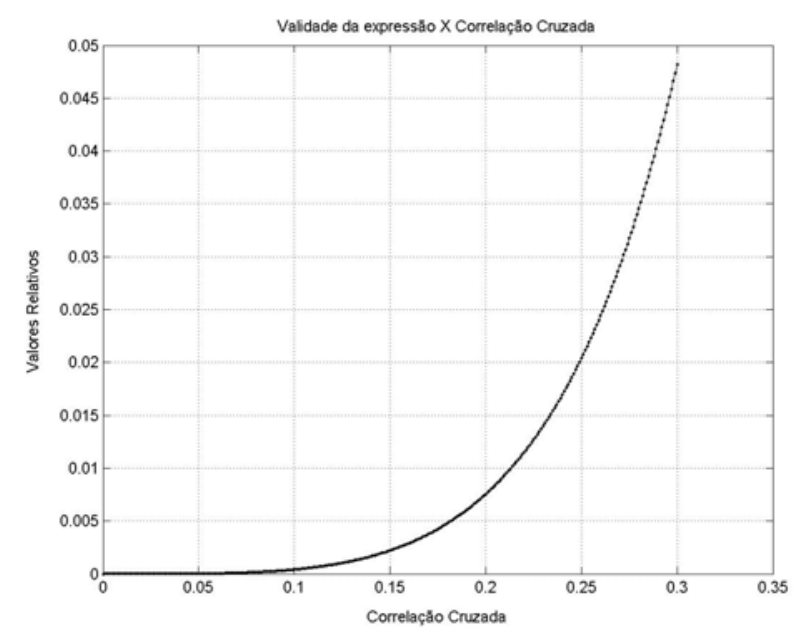

Figura 8. Valores da relação $\frac{4 \rho_{12}^{2} \rho_{21}^{2}}{\left[1-\left(\rho_{12}+\rho_{21}\right)^{2}\right]}$ para diferentes valores de correlação cruzada, considerando sequências aleatórias e média sobre 1500 amostras de correlação cruzada, $\rho_{i k}$.

Uma vez que $4 \rho_{12}^{2} \rho_{21}^{2}<<\left[1-\left(\rho_{12}^{2}+\rho_{21}^{2}\right)\right]^{2}$, pode-se aplicar a aproximação $\sqrt{x^{2}-e} \cong x-\frac{e}{2}$ em $(20)$, resultando $(\mathrm{G}$. MOURA DA SILVA, 2002):

$$
A M E_{2}^{\text {assinc }} \cong 1-\left(\rho^{2}{ }_{12}+\rho^{2}{ }_{21}\right)-2 \rho_{12}^{2} \rho_{21}^{2}
$$

Aplicando-se o operador esperança na equação (21), obtemos uma expressão aproximada para a AME média:

$$
\overline{A M E}_{2}^{\text {assinc }} \cong 1-\left(\overline{\rho_{12}^{2}}+\overline{\rho_{21}^{2}}\right)-2 \overline{\rho_{12}^{2}} \overline{\rho_{21}^{2}}
$$

Outra aproximação feita em (G. MOURA DA SILVA, 2002) foi desconsiderar o termo $2 \rho_{12}^{2} \rho_{21}^{2}$, pois este possui um valor muito pequeno em relação ao termo $1-\left(\overline{\rho_{12}^{2}}+\overline{\rho_{21}^{2}}\right)$, como mostrado na Fig. 9. Analisando-se valores relativos de $\frac{2 \overline{\rho_{12}^{2}} \rho_{21}^{2}}{1-\left(\overline{\rho_{12}^{2}}+\overline{\rho_{21}^{2}}\right)}$, em termos da correlação cruzada; obteve-se a Fig. 10. Note-se que para valores de $\bar{\rho}<0,3$, resultam valores relativos menores que $2 \%$.

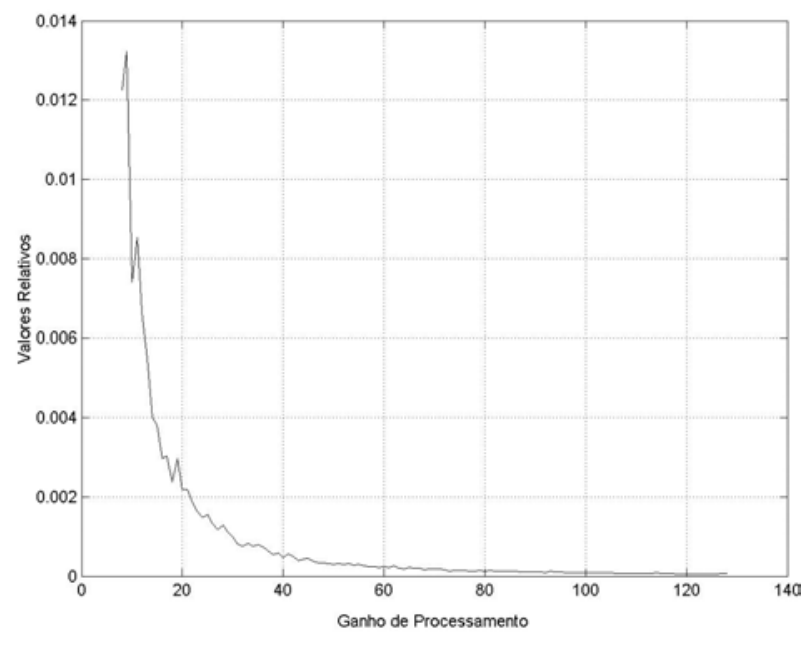

Figura 9. Relação $\frac{2 \overline{\rho_{12}^{2} \rho_{21}^{2}}}{1-\left(\overline{\rho_{12}^{2}}+\overline{\rho_{21}^{2}}\right)}$ em função do ganho de processamento, considerando sequências aleatórias e média sobre 1500 amostras de correlação cruzada, $\rho_{i k}$.

Dessa forma, pode-se obter uma expressão simplificada e relativamente precisa para a AME média assíncrona e 2 usuários:

$$
\overline{A M E}_{2}^{\text {assinc }} \cong 1-\left(\overline{\rho_{12}^{2}}+\overline{\rho_{21}^{2}}\right)
$$

Utilizando o valor médio quadrático para os elementos da matriz de correlação cruzada de seqüências aleatórias mostrada nas equações (8) e (9), pode-se reescrever (18) e (23):

$$
\begin{aligned}
& \overline{A M E}_{2}^{\sin c}=\frac{G-1}{G} \\
& \overline{A M E}_{2}^{a s \sin c}=\frac{3 G-2}{3 G}
\end{aligned}
$$

Expandindo a expressão do carregamento para $K^{\prime}$ usuários, temos:

$$
L=\frac{K-1}{G}=\frac{K^{\prime}-1}{G^{\prime}}
$$

lembrando que para o caso analisado, $K^{\prime}=2$. Podemos obter uma expressão genérica para a $\overline{A M E}$ reescrevendo as equações (24) e (25): 


$$
\overline{A M E}_{2}^{\text {sinc }}=\frac{G-K+1}{G}=1-L
$$

$$
\overline{A M E}_{2}^{\text {assinc }}=\frac{3 G-2(K-1)}{3 G}=\frac{3-2 L}{3}
$$

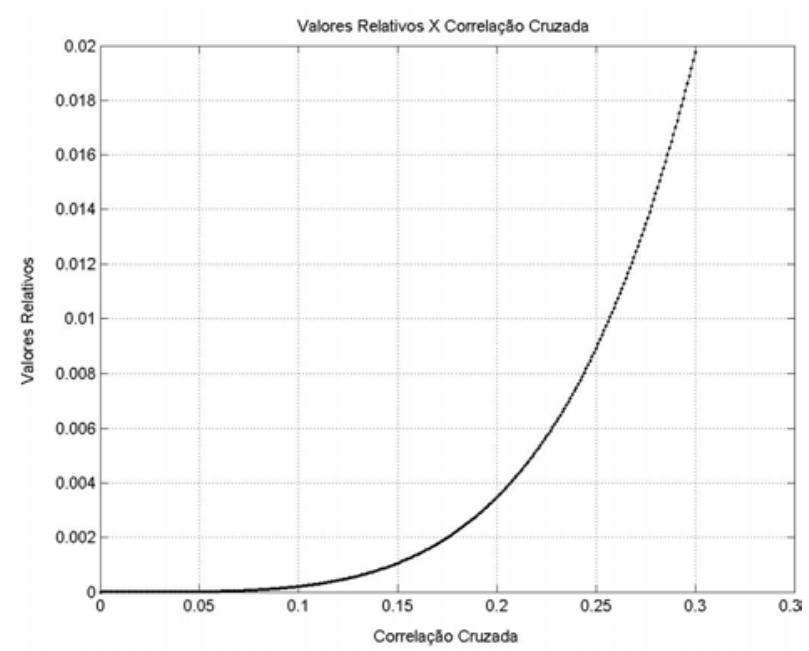

Figura 10. Valores da relação $\frac{2 \overline{p_{12}^{2}} \overline{21}}{1-\left(\overline{\rho_{12}^{2}} \overline{\rho_{21}^{2}}\right)}$ para diferentes valores de correlação cruzada, considerando sequências aleatórias e média sobre 1500 amostras de correlação cruzada, $\rho_{i k}$.

\section{$\overline{R S R I}$ Para o Descorrelacionador}

Com as expressões para a AME simplificadas já encontradas, determinamos a $\overline{R S R I}$ nos casos síncrono e assíncrono para o detector Descorrelacionador.

$$
\begin{gathered}
{\overline{R S R I}_{\text {Decor }}^{\text {sinc }}}^{\text {na }}=\frac{E_{b}(1-L)}{N_{0}} \\
\overline{R S R I}_{\text {Decor }}^{\text {assinc }}=\frac{E_{b}(3-2 L)}{3 N_{0}}
\end{gathered}
$$

Usando as expressões obtidas para a $\overline{R S R I}$ do receptor Descorrelacionador, podemos encontrar a BER substituindo em (2 e 3 ).

\section{Regiões de Aplicabilidade das Expressões para o Descorrelacionador}

A aplicabilidade da expressão analítica simplificada para a BER do receptor Descorrelacionador em canal AWGN síncrono pode ser comparada através da Fig.11.

Neste e nos demais gráficos de desempenho, considerou-se a BER de um sistema com um único usuário ativo, SUB (BPSK).

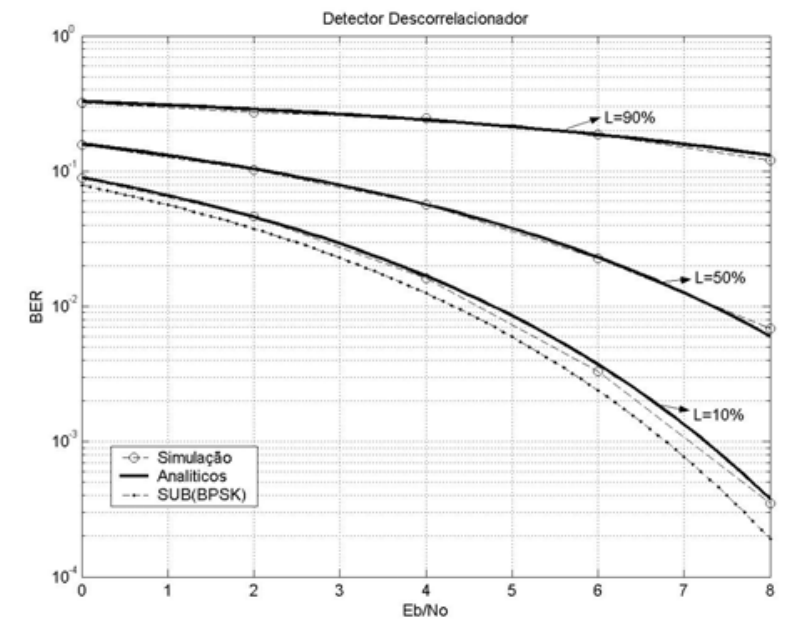

Figura 11. Probabilidade de Erro de Bits para um sistema com $E_{b} / N_{0}$ variável, canal AWGN síncrono, com carregamento de $10 \%, 50 \%$ e $90 \%$, com controle perfeito de potência e expressões analíticas simplificadas.

Pode-se perceber por meio da Fig. 11 que no intervalo $0 \leq E_{b} / N_{0} \leq 8 d B$, a expressão possui uma ótima convergência para qualquer valor de carregamento.

\section{Receptor MMSE}

O detector multi-usuário linear baseado no critério do mínimo erro quadrático médio (MMSE) visa minimizar o erro quadrático médio entre o sinal transmitido e o sinal estimado. Os estágios iniciais de recepção são os mesmos que no detector Convencional, porém no detector MMSE a matriz de transformação linear leva em consideração as estimativas das Amplitudes $(A)$ dos sinais recebidos e a potência do ruído $\left(\sigma_{n}^{2}\right)$. Uma vez que a matriz 
de transformação do MMSE considera o efeito do ruído presente no canal, resulta em desempenho igual ou melhor, em termos de BER, que o Descorrelacionador (S. VERDÚ, 1998).

\section{$\overline{R S R I}$ Para Detector MMSE}

A expressão analítica para o cálculo da BER no caso síncrono, com controle perfeito de potência e sinais equicorrelacionados para o receptor MMSE é bem conhecida e dada por (H. V. POOR; S. VERDÚ, 1997).

$$
P_{M M S E}^{\text {sinc }}=Q\left(\frac{A}{\sigma_{n}} \sqrt{1-\frac{\rho^{2}(K-1)}{1+\frac{\sigma_{n}^{2}}{A^{2}}+(K-2) \rho}}\right)
$$

Reescrevendo (30), em termos de $\frac{E_{b}}{N_{0}}$ e $L$, usando $E\left[\rho_{i j}^{2}\right]=\frac{1}{G}$ e $E\left[\left|\rho_{i j}\right|\right]=\frac{1}{\sqrt{1,57 \cdot G}}$, obtém-se a expressão:

$$
P_{\text {MMSE }}^{\text {sinc }}=Q\left(\sqrt{\frac{2 E_{b}}{N_{0}}\left(1-\frac{L}{1+\frac{N_{0}}{2 E_{b}}+\left(L-\frac{1}{G}\right) \cdot \sqrt{\frac{G}{1,57}}}\right)}\right)
$$

A partir da equação (31), a $\overline{R S R I}$ do MMSE para o caso síncrono e modulação BPSK resulta:

$$
\overline{R S R I}_{\text {MMSE }}^{\text {sine }}=\frac{E_{b}}{N_{0}}\left(1-\frac{L}{1+\frac{N_{0}}{2 E_{b}}+\left(L-\frac{1}{G}\right) \cdot \sqrt{\frac{G}{1,57}}}\right)
$$

Para obtermos a expressão no caso assíncrono, estendendo a análise conduzida em (H. V. POOR; S. VERDÚ, 1997) e reescrevendo (30) em termos de $\frac{E_{b}}{N_{0}}$ e $L$, usando o fato de que para seqüências randômicas $E\left[\rho_{i j}^{2}\right]=\frac{1}{3 G}$ e $E\left[\left|\rho_{i j}\right|\right]=\frac{1}{\sqrt{5,2 \cdot G}}$ obtemos:

$$
P_{\text {MMSE }}^{\text {assinc }}=Q\left(\sqrt{\frac{2 E_{b}}{N_{0}}\left(1-\frac{\frac{L}{3}}{1+\frac{N_{0}}{2 E_{b}}+\left(L-\frac{1}{G}\right) \cdot \sqrt{\frac{G}{5,2}}}\right)}\right)
$$

Desta expressão encontramos a $\overline{R S R I}$ para o caso assíncrono do MMSE, dada por

$$
\overline{\operatorname{RSII}}_{\text {MASE }}^{\text {assinc }}=\frac{E_{b}}{N_{0}}\left(1-\frac{\frac{L}{3}}{1+\frac{N_{0}}{2 E_{b}}+\left(L-\frac{1}{G}\right) \cdot \sqrt{\frac{G}{5,2}}}\right)
$$

A Fig 12 compara a convergência da nova expressão simplificada dada em (31) com a expressão em (30). A nova expressão possui uma ótima convergência para os valores obtidos utilizando a equação (30).

\section{Regiões de Aplicabilidade das Expressões para o MMSE}

Regiões de validade para as expressões (30) (H. V. POOR; S. VERDÚ, 1997) e (31) podem ser visualizadas através da Fig.13. Observe-se que as expressões possuem boa convergência com relação aos resultados obtidos via simulação Monte-Carlo, apenas quando o carregamento é baixo, pois com carregamentos acima de $20 \%$ - 30\% temos uma divergência crescente entre o valor simulado e o valor obtido através das simplificações. Na região de baixo $E_{b} / N_{0}$ a divergência é ainda mais pronunciada, ocorrendo discrepâncias significativas entre o valor simulado e o calculado analiticamente via expressões simplificadas, (30) e (31), para carregamentos ainda menores.

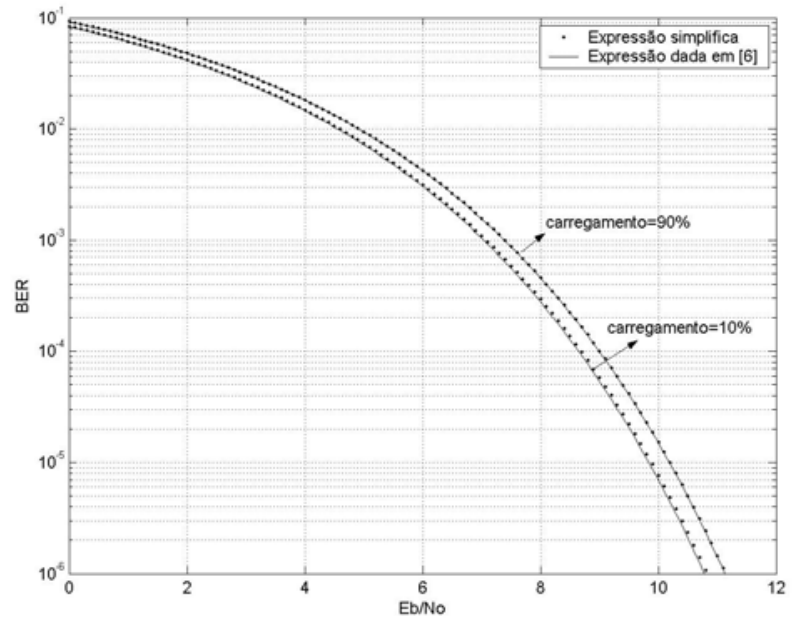

Figura 12. Desempenho comparado para o MMSE síncrono com sinais equicorrelacionados e controleperfeito de potência, equações (30) e (31). 
Uma expressão mais exata para o desempenho do receptor MMSE foi obtida em (H. V. POOR; S. VERDÚ, 1997). Naquela formulação, considerouse todas as possíveis combinações de interferência e desbalanço de potência (razão near-far), resultando em um cálculo hinomial de cômnuto elevado.

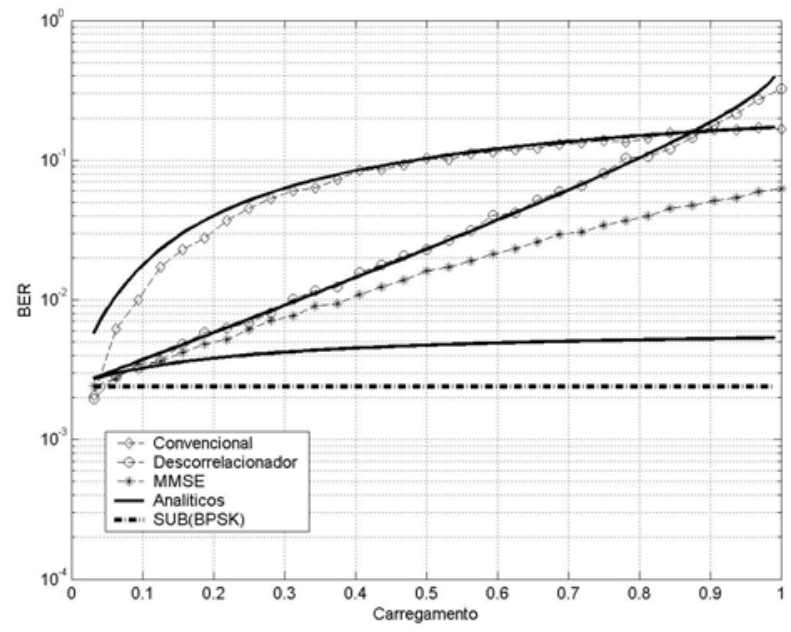

Figura 13. Regiões de aplicabilidade da expressões 30 e 31. "—*-_ Simulação Monte Carlo", "——_Analíticos".

\section{BER para Canal com Desvanecimento}

$\mathrm{Na}$ análise do canal com desvanecimento do tipo Rayleigh, há dois casos de análise a serem abordados, canal plano e o seletivo em freqüência. O canal com desvanecimento plano ocorre quando temos $P=1$ (1 percurso) e o canal seletivo ocorre quando temos $P>1$. Neste trabalho analisaremos um sistema DSCDMA em canal com desvanecimento Rayleigh plano. Por meio da equação (3) podemos facilmente estender a análise para mais de um percurso; porém este caso não será abordado aqui.

\section{Desempenho para os Detectores MUD Lineares}

$\mathrm{Na}$ estimativa de desempenho dos receptores lineares sujeitos a desvanecimento Rayleigh plano, a aplicação das expressões simplificadas encontradas nas seções anteriores foram feitas observando-se o intervalo de validade as expressões, descrito anteriormente.
A Fig 14 apresenta resultados de simulação Monte-Carlo e analíticos para canal AWGN síncrono e carregamento de $L=50 \%$. $A$ simplificação para o detector MMSE não foi utilizada por estar fora da região de aplicabilidade da expressão (31).

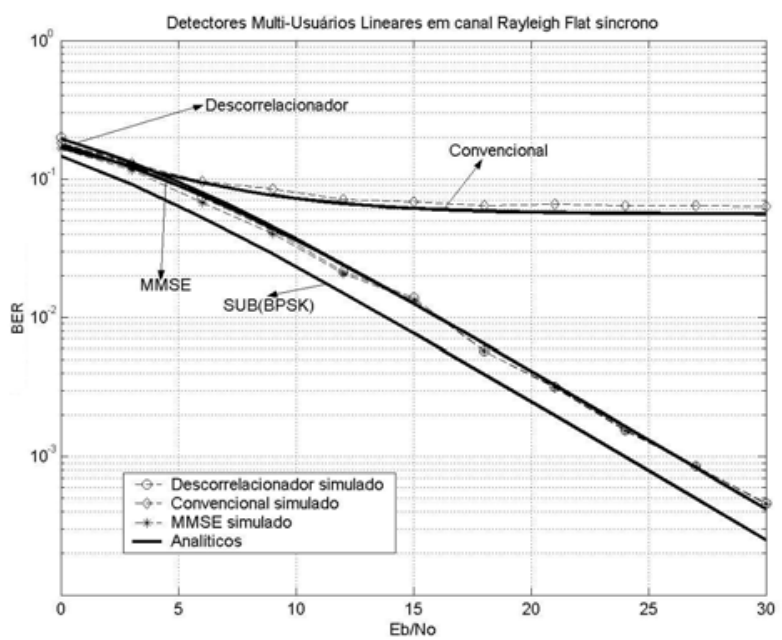

Figura 14. BER para canal AWGN síncrono com carregamento de $50 \%$.

Observe-se na Fig. 15 que a aproximação para o desempenho MMSE, equação (31), torna-se imprecisa com carregamento acima de $15 \%-20 \%$. A região de aplicabilidade da equação (31) é ampliada para $30 \%$ - $50 \%$ caso o sistema opere na região de alto $E_{b} / N_{0}$.

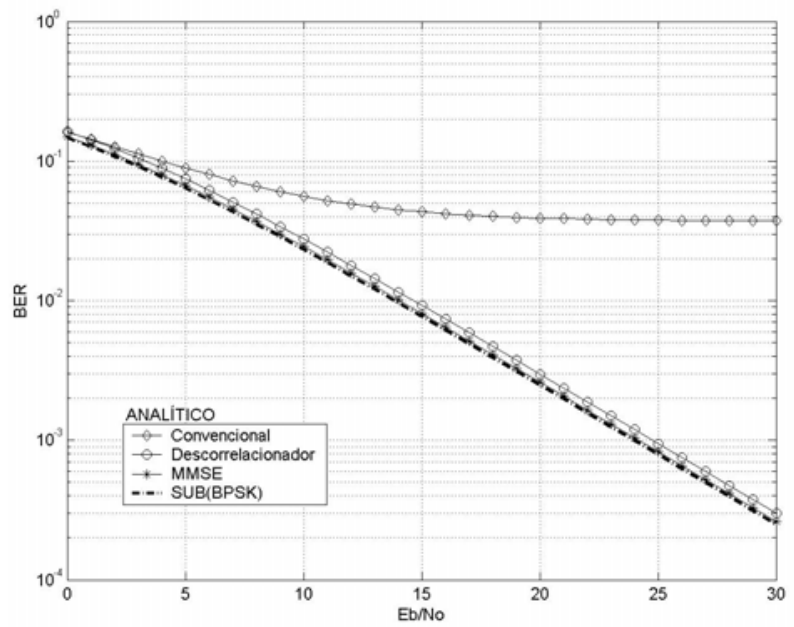

Figura 15. BER para canal AWGN síncrono com $E_{b} / N_{0}=6 d B$ e carregamento variável. 
As Figs 16 e 17 mostram resultados de desempenho para canal Rayleigh Plano, com carregamento de $40 \%$ e $25 \%$, respectivamente. Novamente, não foi utilizada a simplificação para o detector MMSE por estar fora da região de aplicabilidade das expressões (32), (34) e (4).

A aproximação para o Descorrelacionador na Figura 16 mostrou-se excelente para todas as regiões de $E_{b} / N_{0}$ e carregamento de até $40 \%$. A Fig 17 apresenta apenas resultados analíticos para o caso assíncrono.

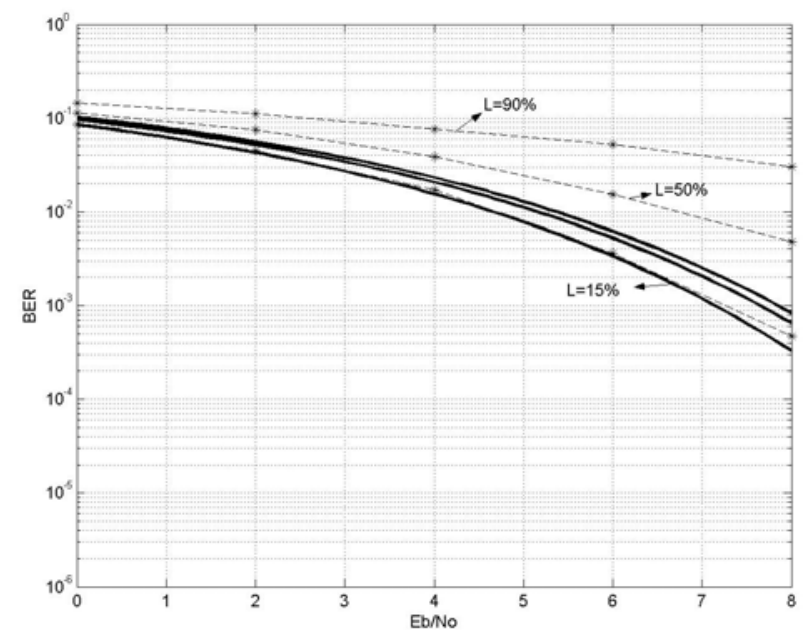

Figura 16. Probabilidade de Erro de Bits para um sistema com $E_{b} / N_{0}$ variável, canal Rayleigh Plano síncrono e carregamento de $40 \%$.

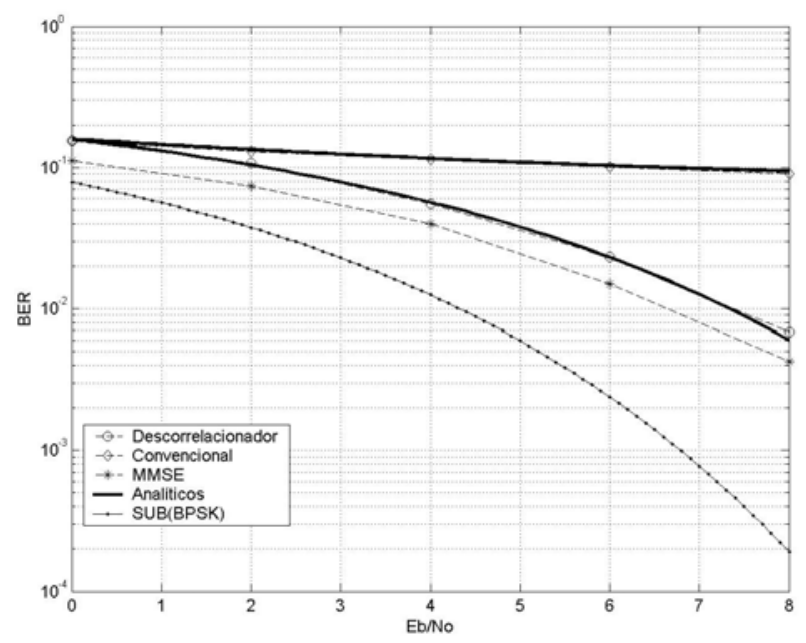

Figura 17. Probabilidades de Erro de Bits analíticas para um sistema com $E_{b} / N_{0}$ variável, canal Rayleigh Plano Assíncrono e carregamento de $25 \%$.

\section{Conclusões}

Expressões simplificadas e relativamente precisas para os detectores multi-usuários lineares descorrelacionador e MMSE foram obtidas e analisadas, comparando-se o grau de precisão com os respectivos resultados obtidos via MCS em função de $E_{b} / N_{0}$ e do carregamento do sistema na faixa de $0 \leq L \leq 1$.

Foi proposta uma expressão alternativa para a equação (30), a partir da determinação dos valores médios para a magnitude da correlação cruzada, equação (10) e (11), e da correlação cruzada quadrática, equação (8) e (9), das seqüências aleatórias.

Foi comprovada a validade da aplicação das expressões analíticas simplificadas e em determinados intervalos estas expressões mostraramse bastante próximas aos resultados obtidos por meio de simulação Monte-Carlo.

Em alguns casos, surgiram algumas discrepâncias entre o resultado obtido mediante as expressões simplificadas e simuladas, fator este causado pelas simplificações feitas na determinação destas expressões.

Isso não invalida as expressões, mas restringe o seu intervalo de aplicação.

Para o MMSE, utilizando seqüências aleatórias, as expressões simplificadas (31) ou (33), válidas apenas para a condição de controle perfeito de potência, podem ser aplicada com relativa acurácia quando o carregamento for menor que $20 \%$, quando o sistema estiver operando sob baixo $E_{b} / N_{0}$ ou menor que $40 \%$ quando em operação na região de alta relação sinal-ruído. Esta imprecisão se deve ao fato da hipótese adotada em (H. V. POOR; S. VERDÚ, 1997) na obtenção de (30) assumir que a interferência de múltiplo acesso segue uma distribuição gaussiana, o que não ocorre quando o sistema estiver operando com um grande número de usuários e pequeno ganho de processamento, isto é operando com altos ou mesmo médios carregamentos. 
Já para o Descorrelacionador as expressões obtidas são válidas para carregamentos de até pelo menos $100 \%$.

Portanto, o uso das expressões simplificadas nos intervalos em que foram comprovados suas convergências com os resultados via simulações MCS reduzem drasticamente o tempo de simulação, pois elas são de cômputo imediato.

\section{Referências}

ABRÃO, T. Canceladores de Interferência Multi-Usuário Aplicados a Sistemas DS/CDMA de Múltipla Taxa. São Paulo: EPUSP, 2001.

JERUCHIM, M. C.; BALABAM, P.; SHANMUGAM, K. S. Simulation of Communication Systems. Plenum Press, New York, 1992.

KAY, S. M. Fundamentals of Statistical Signal Processing: detection theory. Englewood Cliffs, Prentice Hall, v.2, 1993.
MORROW JR., R. K.; LENHERT, J. S. Bit-to-Bit Error Dependence in Slotted DS/CDMA paccket Systems with Random Signature Sequences. Dissertation, Purdue University. IEEE Transactions on Communications, New York, v.37, n.10, Octuber 1989.

POOR, H. V.; VERDÚ, S. Probability of Error in MMSE Multiuser Detection. IEEE Transactions on Communications, New York, v.43, n.3, May 1997.

PROAKIS, J. Digital Communications. McGraw-Hill, New York, 2.ed., 1989

PURSLEY, M. B. Performance Evaluation for PhaseCoded Spread-Spectrum Multiple-Access CommunicatioPart I: System Analysis. IEEE Transactions on Communications, New York, v.25, n.8, August 1977.

SILVA, G. MOURA da Desempenho de Sistemas CDMA com Detector Multi-usuário Descorrelacionador. Campinas: Universidade Estadual de Campinas, 2002. nov.

VERDÚ, S. Multiuser Detection. Cambridge: Cambridge Press, 1998. 